\title{
Autism, Emotion Recognition and the Mirror Neuron System: The Case of Music
}

\author{
Istvan Molnar-Szakacs*, Martha J. Wang, Elizabeth A. Laugeson, \\ Katie Overy, Wai-Ling Wu, Judith Piggot
}

\begin{abstract}
Understanding emotions is fundamental to our ability to navigate and thrive in a complex world of human social interaction. Individuals with Autism Spectrum Disorders (ASD) are known to experience difficulties with the communication and understanding of emotion, such as the nonverbal expression of emotion and the interpretation of emotions of others from facial expressions and body language. These deficits often lead to loneliness and isolation from peers, and social withdrawal from the environment in general. In the case of music however, there is evidence to suggest that individuals with ASD do not have difficulties recognizing simple emotions. In addition, individuals with ASD have been found to show normal and even superior abilities with specific aspects of music processing, and often show strong preferences towards music. It is possible these varying abilities with different types of expressive communication may be related to a neural system referred to as the mirror neuron system (MNS), which has been proposed as deficient in individuals with autism. Music's power to stimulate emotions and intensify our social experiences might activate the MNS in individuals with ASD, and thus provide a neural foundation for music as an effective therapeutic tool. In this review, we present literature on the ontogeny of emotion processing in typical development and in individuals with ASD, with a focus on the case of music.
\end{abstract}

KEYWORDS: limbic system, mirror neurons, music, autism, social interaction

\section{INTRODUCTION}

The processing of affect underpins human experience and serves as the foundation of human interactions in everyday life. This complex process involves the ability to perceive, understand, and respond appropriately to emotional cues. The accurate understanding of these emotional cues is crucial in the assessment of threat, in negotiating transactions, and in the formation of social bonds (1-4).

Autism Spectrum Disorders (ASD) is an umbrella term often used to describe a continuum of diagnoses that include Autistic Disorder, Asperger's Disorder, and

*To whom correspondence should be addressed:

Istvan Molnar-Szakacs, $\mathrm{PhD}$

Tennenbaum Center for the Biology of Creativity

Semel Institute for Neuroscience and Human Behavior

University of California Los Angeles

760 Westwood Plaza

Room C8-846

Los Angeles, CA 90095

Email: imolnar@ucla.edu
Pervasive Developmental Disorder-Not Otherwise Specified (PDD-NOS). Collectively, ASD is characterized by deficits in communication, impairments in social interactions, and restricted and repetitive patterns of behavior (5). One of the core deficits in individuals with ASD is a deficit in emotion processing and communication that prevents them from achieving successful reciprocal social interactions. Laushey and Heflin (2000) have proposed that the most profound and defining issues for individuals with ASD are those difficulties related to poor social functioning (6). Specific social deficits among individuals with ASD often include difficulties in expressing emotions, understanding the emotions of others, and empathizing (7-11), as well as the inability to interpret social cues, assess the formality of social events, and act accordingly (12). The inability to understand the emotional expressions of others and respond appropriately hinders the development of meaningful interpersonal relationships. As a result, individuals with ASD who lack the ability to successfully interpret 
emotional cues are at risk for social rejection. In fact, children with ASD often report poorer quality friendships, including more loneliness, less companionship and less help from their friends (13). Thus, the ramifications of emotion processing difficulties frequently include both emotional and physical isolation.

Deficits in the ability to understand and interpret emotional stimuli among individuals with ASD provides a unique and important opportunity for the study of emotion processing, both for clinical and typically developing populations. In fact, the processing of bodily expressions of emotion has been widely studied in individuals with $\operatorname{ASD}(14,15)$. However, musical emotion processing in ASD has received very little research attention, despite the fact that individuals with ASD seem to respond so positively to music (16). The purpose of this review is to examine studies of emotion processing in typical development and in individuals with ASD, with a focus on music perception and how it may affect the functioning of the mirror neuron system (MNS) in individuals with autism. Our ultimate aim is to evaluate the potential role of music in the study and treatment of socioemotional deficits in individuals with ASD and highlight the need for studies of musical emotion processing, which may hold a promising key to the development of novel, music-based therapeutic interventions.

\section{Typical Development of Emotion Processing}

Perhaps the most fundamental level of social reciprocity is the ability to be in a relationship, which is founded upon the critical component of emotional attunement. The importance of affect exchange is evident from the earliest days of life, when social reciprocity begins with affect sharing and coordination with the caregiver. Trevarthen and Aitken (1994) have proposed that there is an "intrinsic motive formation" that acts as the foundation for the infant's adaptation to her/his environment. This pattern of neural activity works to "direct the infant's brain emotionally" as they self-regulate and try to understand the feelings of others (17). These early exchanges of affect between caregivers and infants lay the foundation for the development of more complex types of communication later in life (18).

Affective exchanges begin almost immediately after birth. Emotional attunement in typically developing children is documented as early as nine minutes of age, where infants preferentially attend to a face-like stimulus (19), and demonstrate a preference for their mother's voice at birth (20). Infants as early as two to three months of age begin to discriminate between several different affective expressions shown by their parents (20). At five months, infants are developing the ability to read affect in the faces of strangers and at six months are able to emotionally attune to their caregivers (21).

Arguably, the foundation for emotional attunement and complex social interactions is dependent upon the emergence and development of joint attention. Joint attention is defined as "the ability to coordinate interest in external objects or events with other people" (22), and is thought to be an attempt to share the experience of objects and events with others (23). Among typically developing infants, the ability for joint attention emerges between 9 and 15 months (24). This is when the infant learns to use gaze to direct the attention of others to objects of interest (25). An inherent interest in other people appears to provide the motivation for some of the behavior that leads to learning to share and track gaze (26-29). Imitative behavior also becomes more prevalent, precise and object-directed at this time. For example, infants will typically imitate the ways in which adults manipulate objects (30).

Studies have shown that beginning in early infancy, typically developing infants begin to use social referencing to make sense of confusing or threatening situations or persons, by looking at the face of their caregiver for information $(31,32)$. Such behaviors that emerge around nine months and continue to develop into the third year of life increase the infants' understanding of self and others as intentional agents, and are based in the gradual development of theory of mind (33). Theory of Mind (ToM) is the ability to understand the desires, intentions, and knowledge of another (34). Typically developing children generally show evidence of a ToM around age four as they begin to understand the perspectives of other persons (35). However, based upon a study examining non-verbal looking time using the violation-of-expectation method, it has been argued that the emergence of a ToM with an implicit understanding of beliefs may even begin to develop as early as 15 months (36). In examining precursors to ToM, Sodian and Thoermer (2008) show that children under the age of three have the ability to use their own and others' epistemic states in communication when engaging in false-belief tasks (37). As children continue to grow, their ability to read affective cues and socially reciprocate becomes more refined. The gradual acquisition of such knowledge allows one to be part of and function successfully in a given culture, by incorporating others' perspectives into one's own mind through cultural learning (33).

\section{Development of Emotion Processing in ASD}

Compared to typically developing children, the developmental trajectory of affect attunement is very 
different among infants with ASD. Even in infancy, children with ASD fail to show the typical interest in human faces, instead showing a preference for inanimate objects (38-41). The automatic mirroring of affective gestures and expressions is also considerably weaker in infants with ASD (42-44). Consequences related to these deficits are displayed during infancy, and extend throughout childhood development. Children with ASD tend to pay less attention to the negative emotions of others compared to typically developing children (45-47). They also appear to have more negative affective exchanges (48), and display less positive emotion to their social partner $(49,50)$ when compared to typically developing peers. The lack of attention paid to emotional cues often causes a rift in social interactions as well as lowering the affective responsivity of children with ASD. Emotional reciprocity is fundamental to the development of social skills and successful social interactions. Due to the combination of deficits exhibited by children with ASD in this realm, their socio-emotional development is frequently stilted.

Deficits in joint attention among individuals with autism are well-documented (51-53). Mundy, Sigman and Kasari (1994) found that joint attention for children with ASD was lower than developmentally delayed and typically developing children (24). In a more recent study, Naber and colleagues (2007) examined different types of joint attention, including basic, associated, and visual. At 24 months, children with ASD showed significantly less overall joint attention correlated with characteristics of autism and developmental level, but at 42 months the associations disappeared. Of the three types of joint attention, only joint visual attention was less at 42 months, suggesting that joint visual attention may be the distinct deficit of concern in the development of joint attention in children with ASD (54).

In research on gaze behavior it has been found that, compared to typically developing children, young children with ASD shift attention between an object and another object more often than between a person and object or between person and person (55). Furthermore, children with ASD spend less time looking at people and more time looking at objects, compared to neurotypical children (55). By contrast, the processing of cartoons with human figures does not show any difference between typically developing children and children with ASD (56). In a study by Klin and colleagues (2002), it was found that when looking at faces, adults with ASD looked at the eyes only half the time of neurotypical adults, but twice as often at mouths and objects (57). A recent neuroimaging study found that brain responses to non-social stimuli (houses) were modulated by attention, both in adults with ASD and a matched control group, but only the control participants demonstrated attentional modulation of face-selective regions during viewing of social (face) stimuli (58). Thus, the participants with ASD demonstrated a lack of attentional modulation for the social stimulus. Taken together, these findings suggest that atypical gaze patterns in individuals with ASD may be related to the reduced salience of social stimuli from the earliest days of life, a deficit that persists into adulthood. Indeed, reduced visual attention to socially salient stimuli may underpin many of the social communication impairments seen in individuals with ASD.

While typically developing infants use social referencing to make sense of confusing or threatening situations (32), children with ASD are less likely to reference another person in these same instances (59) they are unlikely to voluntarily share their experience with others, and avoid initiating triadic interactions, even when guided to do so (60). However, these atypical social behaviors in children with ASD have been suggested to be secondary to impairments in the ability to represent mental states of others, or ToM (61). Normal intellectual and verbal abilities appear to lessen the impact of earlier impairment in ToM, such that in structured situations, individuals with ASD may actually demonstrate ToM abilities $(62,63)$. ToM has been studied in relation to several other aspects of ASD, including how individuals with ASD are less likely to utilize ToM to spontaneously attribute meaning (64), in relation to weak central coherence and event schemas (65), and executive function (66). Taken together, these studies do point to consistent deficits in various aspects of ToM in individuals with ASD.

Social empathy is another area of research that has been widely investigated and related to atypical social interactions among individuals with ASD. Arguably, one of the first steps in social competency is the ability to be empathic. Consequently, when empathy is absent or impaired, social interactions are hindered. Empathy can be categorized into two principle areas: cognitive empathy, which is the process by which one understands another's perspective, and is related to ToM (67), and emotional empathy, which is defined as an emotional response to another's emotional display (67, 68). While some children with high-functioning ASD may have more advanced ToM capabilities (i.e., cognitive empathy), the impairments in identifying emotions in others are still thought to be present (69). Specific deficits in empathy-related processes include the understanding of emotional stimuli, intersubjectivity, and reflecting of affect (70-73), all of which, when deficient have the capacity to negatively impact social reciprocity. Hence, the deficit in 
emotional empathy in individuals with ASD may greatly impede social functioning.

\section{Consequences of Emotional Isolation in ASD}

For individuals with ASD, difficulties in emotion processing are compounded by the inability to accurately perceive and understand emotional cues. The implications of such deficits are many, not the least of which are emotional and physical isolation from family, peers and community. Impairments in social functioning and the inability to understand emotion also commonly result in peer rejection and poor social support; often producing higher levels of loneliness and poor quality of friendships for children with ASD, in comparison to typically developing peers $(13,74)$. On self-report measures of friendship quality, children with ASD endorse less security and trust in friendships, lower levels of companionship, and less helpfulness from friends (13). While loneliness and understanding of friendship are closely linked for typically developing children, Bauminger and Kasari (2000) hypothesize that high-functioning children with ASD may lack the "affective glue" to understand how to utilize their understanding of friendship to reduce loneliness. Thus, the lack of affective bonding between children with ASD and their peers limits the ability to initiate and maintain relationships.

Similarly, many adolescents and adults with ASD also lack close friendships compared to typically developing peers (75). Possibly due to a rise in the complexity of social cues and a greater need for understanding of emotion processing that accompanies developmental maturity, social deficits often become even more prominent as children with ASD enter adolescence (76) and adulthood (77). Although certain symptom aspects of ASD may improve with time and intervention, social difficulties often related to the comprehension of emotions, seem to persist throughout the individual's lifespan and may represent a more chronic deficit in autism $(11,78)$. As adults, the lack of community connections and friendships that are often taken for granted by typically developing persons (75) may contribute to higher rates of depression, anxiety (79), and victimization among individuals with ASD (80). Thus, identifying and developing interventions to improve socio-emotional functioning that are of most help to individuals with ASD is extremely important.

\section{The Mirror Neuron System and Emotion Processing}

In typical development, the sensation that we possess a kind of immediate understanding of what others are doing or feeling is so pervasive and automatic, that we rarely think about it. In fact, this connectedness often allows us to feel others' emotions, as if they were our own. Recently, neuroscience has provided a possible neural mechanism for this matching of sensory information to our own internal representations in the discovery of the mirror neuron system. Researchers working with monkeys, discovered individual neurons in the macaque brain that fire both when an action is executed and when that same action is observed or heard (81), leading these neurons to be called 'mirror neurons', based on this unique functional property. Fadiga and colleagues (1995) provided the first demonstration of a neural system for coding the correspondence between observed and executed actions in humans using single-pulse transcranial magnetic stimulation (TMS). Subsequent work then confirmed these findings, leading researchers to conclude that also in humans, there is a motor resonance system resembling the one described in the monkey (82-86). These data - showing that we use the same neural resources to represent the actions and emotions of others, as our own - provide evidence for a neural substrate that can parsimoniously explain our intuitive 'feeling' of effortlessly understanding others' actions and emotions. Using functional Magnetic Resonance Imaging (fMRI) to localize brain regions showing mirror properties, Iacoboni and colleagues (1999) hypothesized that imitation, which contains both an observation and execution component would lead to a BOLD (blood-oxygen-level dependent; and indirect measure of neural activity) signal increase greater than either action observation or execution alone. This study found two cortical areas that showed this predicted pattern of activity, the posterior inferior frontal gyrus (pIFG) and the rostral sector of the inferior parietal lobule (IPL) (87). Thus, mirror resonance mechanisms subserved by the fronto-parietal MNS are involved in action perception and performance, meaning that this neural system is recruited during both the execution of our own actions, and the observation of the actions of others. Our ability to understand others' actions and emotions, may thus be based in our ability to 'resonate' with others on a motor level, a function that may in fact ground our ability to know about other minds (88).

Although still in its early stages of study, the MNS in humans has already been associated with a wide variety of higher-level functions in addition to action representation, including imitation and imitation learning $(87,89-91)$, intention understanding $(92,93)$, empathy and ToM (94-96), self-representation (97-99), and the evolution of language $(100,101)$. These, and subsequent studies of the human MNS, have greatly contributed to our understanding of the neural bases of perception-action mechanisms, social communication and emotion $(81,102,103)$. Interestingly, these cognitive functions subserved at least in part by the 
MNS - including imitation $(96,104)$, empathy and ToM $(104,105)$, self-representation (105) and language (106) - have all been implicated as deficient in autism. In fact, dysfunction of the MNS has been proposed as a possible cause of autism (96, 107-109).

Due to its importance in imitation, a dysfunction in the MNS may lead to a failure to develop reciprocal social abilities including shared/joint attention, empathy and ToM, as well as gestural recognition and language (96). Deficits in imitation during early childhood development may be at the root of many of the social deficits that manifest themselves during the later development of patients with autism (110). The fundamental similarity between imitation and attribution of mental states is that both processes involve translating from the perspective of another individual to oneself. In belief attribution, one creates a representation of the other person's representation of the world in one's own brain, while the same process occurs during imitation with an action plan originating from another person being translated to one's own frame of reference (111). Autism-specific deficits in imitation have consistently been found $(44,112)$. The errors in imitation of patients with ASD, seem to suggest that they have a deficit in the basic ability of translating action plans from the perspective of others to themselves (111). Differences in emotion processing between typically developing individuals and their peers with ASD are also observable at a neural level. A recent neuroimaging study investigating imitation of emotional facial expressions has shown that children with autism have virtually no activity within the MNS compared to typically developing controls, clearly linking their social isolation to a neural system important for understanding the intentions, actions, and emotions of others (113). Thus, the MNS offers a potential neural substrate for understanding the social difficulties encountered by individuals with ASD, while somewhat paradoxically, the MNS may also offer a neural correlate for the special appreciation of music shown by individuals with ASD.

\section{Music Processing and ASD}

In contrast to the wealth of studies on emotion processing from body gestures and facial expressions of others, emotion processing in music is a relatively new area of research. Music, like facial expressions, can convey emotions, and the ability to enjoy music is a universal human trait - humans tend to relate to music spontaneously and effortlessly. Music also has the powerful ability to stimulate emotions, trigger memories, and intensify our social experiences. Research in the psychology of music has begun to emphasize the intensely social nature of musical activities (114), which may even hold the key to music's potential as a therapeutic and educational tool (115).

In fact, the last decade has seen an explosion of scientific research into the neural basis of music, revealing that different aspects of musical processing recruit almost all regions of the brain-including prefrontal cortex, premotor cortex, motor cortex, somatosensory cortex, temporal lobes, parietal cortex, occipital cortex, cerebellum, and limbic regions including the amygdala and thalamus - unlike any other stimulus or cognitive process (116-119). It has also been shown that components of the limbic system involved in processing emotional stimuli in general the amygdala, the nucleus accumbens (NA), the hypothalamus, the orbitofrontal cortex (OFC), the ventromedial prefrontal cortex (VMPFC), the anterior cingulate cortex (ACC) and the anterior insula (AI) - are also involved during the experience of both pleasant and unpleasant music (120-125). This shows a neural overlap between emotion processing of non-musical stimuli (e.g. pictures, faces) and musical stimuli.

In the classic paper first describing autism, Leo Kanner (1943) presented eleven case studies of children with autism and repeatedly mentioned musical abilities and musical interest in six of the children (126). Since then, researchers have systematically studied the musical processing abilities of individuals with autism, and have shown that while language abilities may be deficient; individuals with ASD seem to process music in similar ways to typically developing individuals $(127,128)$. Moreover, individuals with ASD appear to show a spontaneous preference for musical over verbal stimuli (129), and it has been reported that approximately $40 \%$ of individuals within this population express a special interest in music (130). These reports of prevalent interest in music within the ASD population suggest that musical appreciation may be unimpaired in ASD, and may even represent a particular ability area (126, 131). For example, Applebaum and colleagues (1979) compared three musically naïve children with ASD and three typically developing musically experienced children on their ability to sing back musical stimuli. They found that children with autism performed as well or better than the musically experienced controls (132). Furthermore, a number of studies have indicated that individuals with ASD show superior pitch abilities. For example, Heaton and colleagues (1998) found that children with ASD performed better than control children on a pitch memory task, while performing equally well on a speech sound memory task. In fact, children with autism remembered more tone/picture pairs one week after initial exposure than controls did after 2.5 minutes (133)! More recently, Heaton (2003) found that children with high-functioning autism 
showed enhanced pitch memory and labeling (130). In studies of pitch discrimination, individuals with highfunctioning autism were superior to the comparison group, showing enhanced perception of local pitches (134) and exhibiting an increased sensitivity to pitch on both discrimination and categorization tasks (135).

Individuals with ASD not only show exceptional abilities in the domain of musical processing abilities, but research suggests that affective qualities of music might also be understood by this population. Heaton and colleagues (1999) demonstrated that children with ASD do not differ from typically-developing controls in their ability to perceive happy and sad affect in musical excerpts (127). In a recent follow-up study, it was shown that active music listening is characteristic of children with autism, and that this listening results in the acquisition of culturally embedded knowledge about musical meaning. Based on their findings, the authors conclude that emotion-processing in music may be preserved, and may be closely related to the level of language development, rather than ASD diagnosis (128). This apparently spared ability to understand the affective qualities of music is in marked contrast with the general difficulties in emotional communication and interpretation experienced by individuals with ASD in other domains, such as in social communication (136, 137).

\section{Shared Affective Motion Experience (SAME) - A Mirror Neuron System-Based Model of Music Perception}

How does the brain perceive music? How does emotional music affect the brain of individuals with ASD? Bridging recent neuroimaging findings on the neural bases of intention understanding, action perception and social communication $(90,93,138,139)$ with findings on the neural bases of music perception, it has been proposed that interactions between the MNS and the limbic system may allow the human brain to 'understand' complex patterns of musical signals and provide a neural substrate for the subsequent emotional response $(115,140)$.

The Shared Affective Motion Experience (SAME) model of music perception holds that music is perceived not only as an auditory signal, but also as intentional, hierarchically organized sequences of expressive motor acts behind the signal; and that the MNS allows for corepresentation and sharing of a musical experience between agent and listener. Musical sounds are imbued with intentional expression, evoking the sense of an intentional agent, and leading to the sense of a shared experience in the listener. Within a neural network involving the temporal cortex, the fronto-parietal MNS, and the limbic system, auditory features of the musical signal are processed primarily in the superior temporal gyrus and are combined with structural features of the expressive motion information within the MNS. The anterior insula forms a neural conduit between the MNS and the limbic system (94), allowing incoming information to be evaluated in relation to the perceiver's autonomic and emotional state, thus leading to a complex emotional response to the music. The recruitment of these neural systems in both the agent (musician) and the listener allows for a shared affective motion experience (SAME) (115). As a result, the expressive dynamics of heard sound gestures can be interpreted in terms of the expressive dynamics of personal vocal and physical gestures $(115,140)$.

It might appear puzzling that children with ASD seem to have deficits in the functioning of their MNS, yet are able to experience some of the affective qualities of music. However, it is known that children with ASD are particularly drawn to abstract patterns, and the repetitive, predictable nature of musical sounds may fulfill such a role. It is also possible that through experience and familiarity with these patterns, or indeed through shared musical imitation and synchronization activities, the MNS may become sufficiently engaged for children with ASD to move from the appreciation of musical sound patterns to the appreciation of the emotional state of the agent making them; an agent who appears to behave in predictable, familiar ways that are comforting and companionable, rather than confusing. While the social world with its lack of predictability is often confusing and even frightening for the individual with ASD, the predictable patterns typically found in musical stimuli may provide a reassuring and foreseeable avenue for emotion processing. It may also be highly relevant that music is dependent on auditory processing, since this might allow for attention to the socially salient information, whereas such socially salient information presented visually has been reported as unrewarding (49) and in some cases aversive (141) for individuals with ASD.

During the early development of music as a therapeutic tool, Alvin (1975) and Nordoff and Robbins (1977) (142-144) referred to musical attunement being achieved between the therapist and the child - the therapist would 'meet the child' in music, and through this subtle, rhythmic interaction, communication was facilitated. It is within and through this shared, affective, musical experience that music therapy may have its greatest beneficial effect on socio-emotional behaviors. Accordingly, decades of music therapy research have indicated that autistic children do respond well to music therapy $(142,145)$, as music facilitates and supports their desire to communicate $(146,147)$. Trevarthen (2000) has proposed that the use of music therapy with autistic children may help improve their 
socio-emotional communication abilities, by helping them to develop timing and motor skills. Brownell (2002) has also found that the use of musically adapted storytelling is an effective and viable treatment option for modifying target behaviors of children with autism (148).

While typically developing children often learn basic social rules and emotion processing through observation and imitation of peer behavior and/or specific instruction from caregivers $(149,150)$, children with ASD often require further instruction. Learning to navigate the social world is particularly challenging for persons with ASD, since the natural development and transmission of necessary emotion processing and understanding of social cues requires generally positive and sustained interaction with others. Initiating and sustaining joint attention, which is often absent in children with ASD, is a primary therapeutic goal of music therapy. The SAME model proposes that by creating the feeling of 'being together' - by jointly attending to music through imitation, synchronization, and shared affective experience - these powerful components of musical experience may be key aspects of therapeutic and educational intervention activities for individuals with ASD (115).

Several reviews of the literature have reported consistent and significant improvements in communicative behavior and emotional responsiveness by means of music interventions in individuals with ASD (151-153). While the nature of the musical interventions in individual studies is heterogeneous, a recent meta-analysis of ten studies comparing music to no-music conditions in the treatment of children and adolescents with autism, found an overall effect size of $\mathrm{d}=0.77$, indicating a significant benefit of music intervention. Some of the areas of improvement included: increased appropriate social behaviors and decreased inappropriate, stereotypical, and selfstimulatory behaviors; increased verbalizations, gestures, and comprehension; and increased communicative acts and engagement with others, among other positive effects (152). As the above evidence illustrates, children with ASD may benefit in particular from shared musical experience, as it offers opportunities for supporting the areas of social engagement and nonverbal communication in which they have some of their most profound difficulties (153).

Thus, teaching the skills necessary to comprehend emotion processing has a significant life-long impact for persons with ASD, highlighting the critical need for evidence-based interventions to assist these individuals in improving their social and emotion recognition skills. Further research in the area of emotional music perception and music-based therapies may provide some clues about effective intervention strategies for the treatment of socio-emotional deficits in ASD.

\section{CONCLUSION}

In conclusion, research suggests that individuals with ASD have marked difficulties with emotional communication and social interactions - evidenced early in development by lack of emotional engagement and atypical patterns of inter-subjective behavior. However, individuals with ASD do not appear to have difficulties recognizing simple emotions in music, in fact, they show an affinity for music, and may have some superior abilities with specific aspects of music processing. These findings imply a possible avenue for the development of more effective music-based therapeutic interventions to improve socio-emotional functioning in ASD. The human MNS, by creating a link at the neural level between two interacting agents (e.g. the therapist and the patient), offers a neural substrate for music's therapeutic potential. However, empirical studies - both neural and behavioral - are still required to further clarify the possible beneficial role of music for individuals with ASD. In particular, behavioral studies that investigate the role of music in ameliorating social deficits, such as using musical cues to teach the meaning of other socially salient information, to individuals with ASD will be crucial. Neuroimaging studies will also be essential to help us understand how brain systems, such as the MNS, which reportedly underlie social deficits in ASD, can be activated by music to support social understanding. Such future research has the potential to provide a 'doorway' to evidence-based therapeutic interventions of great benefit to this population.

\section{ACKNOWLEDGEMENTS}

I.M.-Sz., E.A.L. \& K.O. are grateful to the GRAMMY Foundation ${ }^{\circledR}$ grant program for their support of our work in this area.

\section{REFERENCES}

1. Whalen PJ, Rauch SL, Etcoff NL, McInerney SC, Lee MB, Jenike MA. Masked presentations of emotional facial expressions modulate amygdala activity without explicit knowledge. J Neurosci. 1998 Jan 1;18(1):411-8.

2. Whalen PJ, Kagan J, Cook RG, Davis FC, Kim H, Polis S, et al. Human amygdala responsivity to masked fearful eye whites. Science. 2004 Dec 17;306(5704):2061.

3. Klin A, Jones W, Schultz R, Volkmar F. The enactive mind, or from actions to cognition: lessons from autism. Philos Trans $\mathrm{R}$ Soc Lond B Biol Sci. 2003 Feb 28;358(1430):345-60.

4. Iacoboni M, Lieberman MD, Knowlton BJ, Molnar-Szakacs I, Moritz M, Throop CJ, et al. Watching social interactions produces dorsomedial prefrontal and medial parietal BOLD fMRI signal increases compared to a resting baseline. NeuroImage. 2004 Mar;21(3):1167-73. 
5. APA. Diagnostic and Statistical Manual of Mental Disorders, Fourth Edition, Text Revision (DSM-IV-TR). Fourth Edition ed. Washington, DC: American Psychiatric Association 2000.

6. Laushey KM, Heflin LJ. Enhancing social skills of kindergarten children with autism through the training of multiple peers as tutors. Journal of autism and developmental disorders. 2000 Jun;30(3):183-93.

7. Baron-Cohen S. Mindblindness: An Essay on Autism and Theory of Mind. Boston, MA: MIT Press/Bradford Books 1995.

8. Travis LL, Sigman M. Social deficit and interpersonal relationship in autism. Mental Retardation and Developmental Disabilities. 1998;4:65-72.

9. Volkmar FR, Klin A, Schultz RT, Rubin E, Bronen R. Asperger's disorder. Am J Psychiatry. 2000 Feb;157(2):262-7.

10. Krasny L, Williams BJ, Provencal S, Ozonoff S. Social skills interventions for the autism spectrum: essential ingredients and a model curriculum. Child Adolesc Psychiatr Clin N Am. 2003 Jan;12(1):107-22.

11. Frith U. Emanuel Miller lecture: confusions and controversies about Asperger syndrome. Journal of child psychology and psychiatry, and allied disciplines. 2004 May;45(4):672-86.

12. Griffin HC, Griffin LW, Fitch CW, Albera V, Gingras H. Educational interventions for individuals with Asperger syndrome. Intervention in School and Clinic. 2006;41(150155).

13. Bauminger N, Kasari C. Loneliness and friendship in highfunctioning children with autism. Child Dev. 2000 MarApr;71(2):447-56.

14. Pelphrey KA, Sasson NJ, Reznick JS, Paul G, Goldman BD, Piven J. Visual scanning of faces in autism. Journal of autism and developmental disorders. 2002 Aug;32(4):249-61.

15. Wang AT, Dapretto M, Hariri AR, Sigman M, Bookheimer SY. Neural correlates of facial affect processing in children and adolescents with autism spectrum disorder. Journal of the American Academy of Child and Adolescent Psychiatry. 2004 Apr;43(4):481-90.

16. Heaton P, Williams K, Cummins O, Happe F. Autism and pitch processing splinter skills: a group and subgroup analysis. Autism. 2008 Mar;12(2):203-19.

17. Trevarthen C, Aitken KJ. Brain development, infant communication, and empathy disorders:

Intrinsic factors in child mental health. Development and Psychopathology. 1994;6(597-633).

18. Stern DN. The interpersonal world of the human infant. New York: Basic Books 1985.

19. Goren CC, Sarty M, Wu PY. Visual following and pattern discrimination of face-like stimuli by newborn infants. Pediatrics. 1975 Oct;56(4):544-9.

20. DeCasper AJ, Fifer WP. Of human bonding: newborns prefer their mothers' voices. Science. 1980 Jun 6;208(4448):1174-6.

21. Rochat P, Striano T. Social-cognitive development in the first year. In: Rochat P, ed. Early Social Cognition: Understanding others in the first months of life. Mahwah, NJ Lawrence Erlbaum Associates 1999.

22. Siller M, Sigman M. Modeling longitudinal change in the language abilities of children with autism: parent behaviors and child characteristics as predictors of change. Dev Psychol. 2008 Nov;44(6):1691-704.

23. Moore C, Dunham PJ. Joint attention: Its origins and role in development. Hillsdale, N.J.: Lawrence Erlbaum Associates 1995.

24. Mundy P, Newell L. Attention, Joint Attention, and Social Cognition. Curr Dir Psychol Sci. 2007 Oct 1;16(5):269-74.

25. Butterworth G, Cochran E. Towards a mechanism of joint visual attention in human infancy. International Journal of
Behavioral Development. 1980;3:253-72.

26. Carpenter M, Nagell K, Tomasello M. Social cognition, joint attention, and communicative competence from 9 to 15 months of age. Monogr Soc Res Child Dev. 1998;63(4):i-vi, 1-143.

27. Dawson G, Toth K, Abbott R, Osterling J, Munson J, Estes A, et al. Early social attention impairments in autism: social orienting, joint attention, and attention to distress. Dev Psychol. 2004 Mar;40(2):271-83.

28. Leekam SR, Lopez B, Moore C. Attention and joint attention in preschool children with autism. Dev Psychol. 2000 Mar;36(2):261-73

29. Sigman M, Capps L. Children with Autism: A Develomental Perspective. Cambridge, MA: Harvard University Press 1997.

30. Meltzoff AN. Infant imitation and memory: Nine-month-olds in immediate and deferred tests. Child Development. 1988;59(1):217-25.

31. Klinnert MD, Campos J, Sorce J, Emde RN, Svejda MJ. Social Referencing: Emotional Expressions as Behavior Regulators. In: Plutchik R, Kellerman H, eds. Emotion: Theory, research, and experience: Emotions in early development. Orlando, FL: Academic Press 1983:57-86.

32. Hornik R, Risenhoover N, Gunnar M. The effects of maternal positive, neutral, and negative affective communications on infant responses to new toys. Child Dev. 1987;58:937-44.

33. Tomasello M, Kruger AC, Ratner HH. Cultural learning. Behav Brain Sci. 1993;16(495-552).

34. Premack DG, Woodruff G. Does the chimpanzee have a theory of mind? Behav Brain Sci. 1978;1:515-26.

35. Hadjikhani N, Joseph RM, Snyder J, Tager-Flusberg H. Abnormal activation of the social brain during face perception in autism. Hum Brain Mapp. 2007 May;28(5):441-9.

36. Onishi KH, Baillargeon R. Do 15-month-old infants understand false beliefs? Science. 2005 Apr 8;308(5719):2558.

37. Sodian B, Thoermer C. Precursors to a theory of mind in infancy: perspectives for research on autism. Q J Exp Psychol (Colchester). 2008 Jan;61(1):27-39.

38. Baird G, Charman T, Baron-Cohen S, Cox A, Swettenham J, Wheelwright $\mathrm{S}$, et al. A screening instrument for autism at 18 months of age: a 6-year follow-up study. Journal of the American Academy of Child and Adolescent Psychiatry. 2000 Jun;39(6):694-702.

39. Baron-Cohen S, Cox A, Baird G, Swettenham J, Nightingale $\mathrm{N}$, Morgan K, et al. Psychological markers in the detection of autism in infancy in a large population. Br J Psychiatry. 1996 Feb;168(2):158-63.

40. Cohen DJ, Volkmar FR. Handbook of Autism and Pervasive Developmental Disorders. 2nd ed. New York, NY: John Wiley \& Sons 1997.

41. Osterling J, Dawson G. Early recognition of children with autism: a study of first birthday home videotapes. Journal of autism and developmental disorders. 1994 Jun;24(3):247-57.

42. Hobson RP, Lee A. Imitation and identification in autism. Journal of child psychology and psychiatry, and allied disciplines. 1999 May;40(4):649-59.

43. Williams JH, Whiten A, Singh T. A systematic review of action imitation in autistic spectrum disorder. Journal of autism and developmental disorders. 2004 Jun;34(3):285-99.

44. Rogers S. An examination of the imitation deficit in autism. In: Nadel J, Butterworth G, eds. Imitation in infancy. Cambridge: Cambridge University Press 1999:255-83.

45. Bacon AL, Fein D, Morris R, Waterhouse L, Allen D. The responses of autistic children to the distress of others. Journal of autism and developmental disorders. 1998 Apr;28(2):12942.

46. Corona R, Dissanayake C, Arbelle S, Wellington P, Sigman M. 
Is affect aversive to young children with autism? Behavioral and cardiac responses to experimenter distress. Child Dev. 1998 Dec;69(6):1494-502.

47. Sigman MD, Kasari C, Kwon JH, Yirmiya N. Responses to the negative emotions of others by autistic, mentally retarded, and normal children. Child Dev. 1992 Aug;63(4):796-807.

48. Yirmiya N, Kasari C, Sigman M, Mundy P. Facial expressions of affect in autistic, mentally retarded and normal children. Journal of child psychology and psychiatry, and allied disciplines. 1989 Sep;30(5):725-35.

49. Dawson G, Hill D, Spencer A, Galpert L, Watson L. Affective exchanges between young autistic children and their mothers. J Abnorm Child Psychol. 1990 Jun;18(3):335-45.

50. Snow ME, Hertzig ME, Shapiro T. Expression of emotion in young autistic children. Journal of the American Academy of Child and Adolescent Psychiatry. 1987 Nov;26(6):836-8.

51. Loveland KA, Landry SH. Joint attention and language in autism and developmental language delay. Journal of autism and developmental disorders. 1986 Sep;16(3):335-49.

52. Mundy P, Sigman M, Ungerer J, Sherman T. Defining the social deficits of autism: the contribution of non-verbal communication measures. Journal of child psychology and psychiatry, and allied disciplines. 1986 Sep;27(5):657-69.

53. Curcio F. Sensorimotor functioning and communication in mute autistic children. Journal of autism and childhood schizophrenia. 1978 Sep;8(3):281-92.

54. Naber FB, Swinkels SH, Buitelaar JK, Dietz C, van Daalen E, Bakermans-Kranenburg MJ, et al. Joint attention and attachment in toddlers with autism. J Abnorm Child Psychol. 2007 Dec;35(6):899-911.

55. Swettenham J, Baron-Cohen S, Charman T, Cox A, Baird G, Drew A, et al. The frequency and distribution of spontaneous attention shifts between social and nonsocial stimuli in autistic, typically developing, and nonautistic developmentally delayed infants. Journal of child psychology and psychiatry, and allied disciplines. $1998 \mathrm{Jul} ; 39(5): 747-53$.

56. van der Geest JN, Kemner C, Camfferman G, Verbaten MN, van Engeland $\mathrm{H}$. Looking at images with human figures: comparison between autistic and normal children. Journal of autism and developmental disorders. 2002 Apr;32(2):69-75.

57. Klin A, Jones W, Schultz R, Volkmar F, Cohen D. Visual fixation patterns during viewing of naturalistic social situations as predictors of social competence in individuals with autism. Arch Gen Psychiatry. 2002 Sep;59(9):809-16.

58. Bird G, Catmur C, Silani G, Frith C, Frith U. Attention does not modulate neural responses to social stimuli in autism spectrum disorders. NeuroImage. 2006 Jul 15;31(4):1614-24.

59. Kasari C, Sigman M. Expression and understanding of emotion in atypical development: Autism and Down syndrome. In: Lewis M, Sullivan MW, eds. Emotional development in atypical children. Mahwah, NJ: Erlbaum Associates 1996.

60. Baron-Cohen S. Perceptual role taking and protodeclarative pointing in autism. British Journal of Developmental Psychology. 1989;7:113-27.

61. Baron-Cohen S, Leslie AM, Frith U. Does the autistic child have a "theory of mind"? Cognition. 1985 Oct;21(1):37-46.

62. Dahlgren SO, Trillingsgaard A. Theory of mind in nonretarded children with autism and Asperger's syndrome. A research note. Journal of child psychology and psychiatry, and allied disciplines. $1996 \mathrm{Sep}$;37(6):759-63.

63. Bowler DM. "Theory of mind" in Asperger's syndrome. Journal of child psychology and psychiatry, and allied disciplines. 1992 Jul;33(5):877-93.

64. Klin A. Attributing social meaning to ambiguous visual stimuli in higher-functioning autism and Asperger syndrome: The
Social Attribution Task. Journal of child psychology and psychiatry, and allied disciplines. 2000 Oct;41(7):831-46.

65. Loth E, Gomez JC, Happe F. Event schemas in autism spectrum disorders: the role of theory of mind and weak central coherence. Journal of autism and developmental disorders. 2008 Mar;38(3):449-63.

66. Pellicano E. Links between theory of mind and executive function in young children with autism: clues to developmental primacy. Dev Psychol. 2007 Jul;43(4):974-90.

67. de Waal FBM. Putting the altruism back into altruism: the evolution of empathy. Annual review of psychology. 2008;59:279-300.

68. Davis M. Measuring individuals differences in empathy: Evidence for a multidimensional approach Journal of Personality and Social Psychology. 1983;44:113-26.

69. Downs A, Smith T. Emotional understanding, cooperation, and social behavior in high-functioning children with autism. Journal of autism and developmental disorders. 2004 Dec;34(6):625-35.

70. Capps L, Kasari C, Yirmiya N, Sigman M. Parental perception of emotional expressiveness in children with autism. J Consult Clin Psychol. 1993 Jun;61(3):475-84.

71. McIntosh DN, Reichmann-Decker A, Winkielman P, Wilbarger JL. When the social mirror breaks: deficits in automatic, but not voluntary, mimicry of emotional facial expressions in autism. Dev Sci. 2006 May;9(3):295-302.

72. Moody EJ, McIntosh DN. Mimicry and autism: Bases and consequences of rapid, automatic matching behavior. In: Rogers SJ, Williams J, eds. Imitation and the social mind: Autism and typical development New York: Guilford Press 2006:71-95.

73. Stel M, van den Heuvel C, Smeets RC. Facial feedback mechanisms in autistic spectrum disorders. Journal of autism and developmental disorders. 2008 Aug;38(7):1250-8.

74. Chamberlain B, Kasari C, Rotheram-Fuller E. Involvement or isolation? The social networks of children with autism in regular classrooms. Journal of autism and developmental disorders. 2007 Feb;37(2):230-42.

75. Baxter A. The power of friendship. Journal of Developmental Disabilities. 1997;5:112-7.

76. Tantam D. The challenge of adolescents and adults with Asperger syndromes. Child And Adolescent Psychiatric Clinics of North America. 2003;12:143-63.

77. Klin A, Volkmar FR. Asperger syndrome: diagnosis and external validity. Child Adolesc Psychiatr Clin N Am. 2003 Jan;12(1):1-13, v.

78. Orsmond GI, Krauss MW, Seltzer MM. Peer relationships and social and recreational activities among adolescents and adults with autism. Journal of autism and developmental disorders. 2004 Jun;34(3):245-56.

79. Attwood T. Cognitive behaviour therapy for children and adults with Asperger's syndrome. Behaviour Change. 2004;21:147-61

80. Shtayermman O. Peer victimization in adolescents and young adults diagnosed with Asperger's Syndrome: a link to depressive symptomatology, anxiety symptomatology and suicidal ideation. Issues Compr Pediatr Nurs. 2007 JulSep;30(3):87-107.

81. Rizzolatti G, Craighero L. The mirror-neuron system. Annu Rev Neurosci. 2004;27:169-92.

82. Fadiga L, Fogassi L, Pavesi G, Rizzolatti G. Motor facilitation during action observation: a magnetic stimulation study. J Neurophysiol. 1995 Jun;73(6):2608-11.

83. Strafella AP, Paus T. Modulation of cortical excitability during action observation: a transcranial magnetic stimulation study. Neuroreport. 2000 Jul 14;11(10):2289-92. 
84. Borroni P, Baldissera F. Activation of motor pathways during observation and execution of hand movements. Soc Neurosci. 2008;3(3-4):276-88.

85. Gangitano M, Mottaghy FM, Pascual-Leone A. Phase-specific modulation of cortical motor output during movement observation. Neuroreport. 2001 May 25;12(7):1489-92.

86. Montagna M, Cerri G, Borroni P, Baldissera F. Excitability changes in human corticospinal projections to muscles moving hand and fingers while viewing a reaching and grasping action. Eur J Neurosci. 2005 Sep;22(6):1513-20.

87. Iacoboni M, Woods RP, Brass M, Bekkering H, Mazziotta JC, Rizzolatti G. Cortical mechanisms of human imitation. Science. 1999;286(5449):2526-8.

88. Gallese V. Before and below 'theory of mind': embodied simulation and the neural correlates of social cognition. Phil Trans R Soc B. 2007;362:659-69.

89. Koski L, Iacoboni M, Dubeau MC, Woods RP, Mazziotta JC. Modulation of cortical activity during different imitative behaviors. J Neurophysiol. 2003 Jan;89(1):460-71.

90. Molnar-Szakacs I, Iacoboni M, Koski L, Mazziotta JC. Functional Segregation within Pars Opercularis of the Inferior Frontal Gyrus: Evidence from fMRI Studies of Imitation and Action Observation. Cereb Cortex. 2005;15:986-94.

91. Buccino G, Vogt S, Ritzl A, Fink GR, Zilles K, Freund HJ, et al. Neural circuits underlying imitation learning of hand actions: an event-related fMRI study. Neuron. 2004 Apr 22;42(2):323-34.

92. Gallese V, Goldman A. Mirror neurons and the simulation theory of mind-reading. Trends in Cognitive Sciences. 1998 December 1998;2(12):493-501.

93. Iacoboni M, Molnar-Szakacs I, Gallese V, Buccino G, Mazziotta JC, Rizzolatti G. Grasping the intentions of others with one's own mirror neuron system. PLoS Biol. 2005 Mar;3(3):e79.

94. Carr L, Iacoboni M, Dubeau MC, Mazziotta JC, Lenzi GL. Neural mechanisms of empathy in humans: a relay from neural systems for imitation to limbic areas. Proc Natl Acad Sci U S A. 2003 Apr 29;100(9):5497-502.

95. Leslie KR, Johnson-Frey SH, Grafton ST. Functional imaging of face and hand imitation: towards a motor theory of empathy. Neuroimage. 2004 Feb;21(2):601-7.

96. Williams JH, Whiten A, Suddendorf T, Perrett DI. Imitation, mirror neurons and autism. Neuroscience and biobehavioral reviews. 2001;25(4):287-95.

97. Molnar-Szakacs I, Arzy S. Searching for an integrated selfrepresentation. Communicative \& Integrative Biology. 2009;2(4):1-3.

98. Uddin LQ, Kaplan JT, Molnar-Szakacs I, Zaidel E, Iacoboni M. Self-face recognition activates a frontoparietal "mirror" network in the right hemisphere: an event-related fMRI study. NeuroImage. 2005 Apr 15;25(3):926-35.

99. Uddin LQ, Molnar-Szakacs I, Zaidel E, Iacoboni M. rTMS to the right inferior parietal lobule disrupts self-other discrimination. Soc Cogn Affect Neurosci. 2006;1(1):65-71.

100. Arbib MA. From monkey-like action recognition to human language: an evolutionary framework for neurolinguistics. Behav Brain Sci. 2005 Apr;28(2):105-24; discussion 25-67.

101. Rizzolatti G, Arbib M. Language within our grasp. Trends in Neurosciences. 1998;21(5):188-94.

102. Iacoboni M. Imitation, empathy, and mirror neurons. Annual review of psychology. 2009;60:653-70.

103. Pineda JA. Sensorimotor cortex as a critical component of an 'extended' mirror neuron system: Does it solve the development, correspondence, and control problems in mirroring? Behav Brain Funct. 2008;4:47.

104. Charman T, Swettenham J, Baron-Cohen S, Cox A, Baird G,
Drew A. Infants with autism: an investigation of empathy, pretend play, joint attention, and imitation. Dev Psychol. 1997 Sep;33(5):781-9.

105. Lombardo MV, Barnes JL, Wheelwright SJ, Baron-Cohen S. Self-referential cognition and empathy in autism. PLoS ONE. 2007;2(9):e883.

106. Baltaxe C. Pragmatic deficits in the language of autistic adolescents. J Pediatr Psychol. 1977;2(4):176-80.

107. Williams JH, Waiter GD, Gilchrist A, Perrett DI, Murray AD, Whiten A. Neural mechanisms of imitation and 'mirror neuron' functioning in autistic spectrum disorder. Neuropsychologia. 2006;44(4):610-21.

108. Oberman LM, Ramachandran VS. The simulating social mind: the role of the mirror neuron system and simulation in the social and communicative deficits of autism spectrum disorders. Psychol Bull. 2007 Mar;133(2):310-27.

109. Williams JH. Self-other relations in social development and autism: multiple roles for mirror neurons and other brain bases. Autism Res. 2008 Apr;1(2):73-90.

110. Rogers SJ, Pennington BF. A theoretical approach to the deficits in infantile autism. Dev Psychopathol. 1991;3:137-62.

111. Whiten A, Brown JD. Imitation and the reading of other minds: perspectives from the study of autism, normal children and non-human primates. In: Braten $\mathrm{S}$, ed. Intersubjective Communication and Emotion in Early Ontogeny. Cambridge, UK: Cambridge University Press 1999:260-80.

112. Smith IM, Bryson SE. Imitation and action in autism: a critical review. Psychol Bull. 1994 Sep;116(2):259-73.

113. Dapretto M, Davies MS, Pfeifer JH, Scott AA, Sigman M, Bookheimer SY, et al. Understanding emotions in others: mirror neuron dysfunction in children with autism spectrum disorders. Nat Neurosci. 2006 Jan;9(1):28-30.

114. Hargreaves DJ, North AC. The functions of music in everyday life: Redefining the social in music psychology. Psychology of Music. 1999;27:71-83.

115. Overy K, Molnar-Szakacs I. Being together in time: Musical experience and the mirror neuron system. Music Perception. 2009;26:489-504.

116. Chartrand J-P, Peretz I, Belin P. Auditory recognition expertise and domain specificity. Brain Research. 2008;1220:191-8.

117. Koelsch S, Siebel WA. Towards a neural basis of music perception. Trends Cogn Sci. 2005 Dec;9(12):578-84.

118. Zatorre R. Music, the food of neuroscience? Nature. 2005 Mar 17;434(7031):312-5.

119. Zatorre RJ, Chen JL, Penhune VB. When the brain plays music: auditory-motor interactions in music perception and production. Nat Rev Neurosci. 2007 Jul;8(7):547-58.

120. Pessoa L. On the relationship between emotion and cognition. Nat Rev Neurosci. 2008 Feb;9(2):148-58.

121. Blood AJ, Zatorre RJ, Bermudez P, Evans AC. Emotional responses to pleasant and unpleasant music correlate with activity in paralimbic brain regions. Nat Neurosci. 1999 Apr;2(4):382-7.

122. Blood AJ, Zatorre RJ. Intensely pleasurable responses to music correlate with activity in brain regions implicated in reward and emotion. Proc Natl Acad Sci U S A. 2001 Sep 25;98(20):11818-23.

123. Gosselin N, Peretz I, Johnsen E, Adolphs R. Amygdala damage impairs emotion recognition from music. Neuropsychologia. 2007 Jan 28;45(2):236-44.

124. Koelsch S, Fritz T, DY VC, Muller K, Friederici AD. Investigating emotion with music: an fMRI study. Hum Brain Mapp. 2006 Mar;27(3):239-50.

125. Koelsch S, Fritz T, Schlaug G. Amygdala activity can be modulated by unexpected chord functions during music listening. Neuroreport. 2008 Dec 3;19(18):1815-9. 
126. Kanner L. Autistic disturbances of affective contact. Nervous Child. 1943;2:217-50.

127. Heaton P, Hermelin B, Pring L. Can children with autistic spectrum disorders perceive affect in music? An experimental investigation. Psychological medicine. 1999 Nov;29(6):140510 .

128. Heaton P, Hudry K, Ludlow A, Hill E. Superior discrimination of speech pitch and its relationship to verbal ability in autism spectrum disorders. Cognitive neuropsychology. 2008 Sep;25(6):771-82.

129. Blackstock EG. Cerebral asymmetry and the development of early infantile autism. Journal of autism and childhood schizophrenia. 1978 Sep;8(3):339-53.

130. Heaton P. Pitch memory, labelling and disembedding in autism. Journal of child psychology and psychiatry, and allied disciplines. 2003 May;44(4):543-51.

131. Rimland B, Hill AL. Idiot savants. In: Wortis J, ed. Mental retardation and developmental disabilities. New York: Plenum Press 1984:155-69.

132. Applebaum E, Egel AL, Koegel RL, Imhoff B. Measuring musical abilities of autistic children. Journal of autism and developmental disorders. 1979 Sep;9(3):279-85.

133. Heaton P, Hermelin B, Pring L. Autism and pitch processing: A precursor for savant musical ability? Music Perception. 1998;154:291-305.

134. Mottron L, Peretz I, Menard E. Local and global processing of music in high-functioning persons with autism: beyond central coherence? Journal of child psychology and psychiatry, and allied disciplines. 2000 Nov;41(8):1057-65.

135. Bonnel A, Mottron L, Peretz I, Trudel M, Gallun E, Bonnel AM. Enhanced pitch sensitivity in individuals with autism: a signal detection analysis. J Cogn Neurosci. 2003 Feb $15 ; 15(2): 226-35$.

136. Langdell T. Recognition of faces: an approach to the study of autism. Journal of child psychology and psychiatry, and allied disciplines. 1978 Jul;19(3):255-68.

137. Kasari C, Sigman M, Mundy P, Yirmiya N. Affective sharing in the context of joint attention interactions of normal, autistic, and mentally retarded children. Journal of autism and developmental disorders. 1990 Mar;20(1):87-100.

138. Molnar-Szakacs I, Wu AD, Robles FJ, Iacoboni M. Do you see what I mean? Corticospinal excitability during observation of culture-specific gestures. PLoS ONE. 2007;2(7):e626.

139. Molnar-Szakacs I, Kaplan J, Greenfield PM, Iacoboni M. Observing complex action sequences: The role of the frontoparietal mirror neuron system. NeuroImage. 2006 Nov 15;33(3):923-35.
140. Molnar-Szakacs I, Overy K. Music and mirror neurons: from motion to 'e'motion. Soc Cogn Affect Neurosci. 2006 Dec;1(3):235-41.

141. Dalton KM, Nacewicz BM, Johnstone T, Schaefer HS, Gernsbacher MA, Goldsmith HH, et al. Gaze fixation and the neural circuitry of face processing in autism. Nat Neurosci. 2005 Apr;8(4):519-26.

142. Alvin J. Music therapy for the autistic child. London: Oxford University Press 1975.

143. Alvin J, Warwick A. Music Therapy for the Autistic Child. London, UK: Oxford University Press 1991.

144. Nordoff P, Robbins C. Creative Music Therapy. New York, USA: The John Day Company 1977.

145. Edgerton CL. The effect of improvisational music therapy on the communicative behaviors of autistic children. Journal of music therapy. 1994;31:31-62.

146. Thaut M. A music therapy treatment model for autistic children. Music Therapy Perspectives. 1984;1(4):7-13.

147. Trevarthen C. Autism as a neurodevelopmental disorder affecting communication and learning in early childhood: prenatal origins, post-natal course and effective educational support. Prostaglandins, leukotrienes, and essential fatty acids. 2000 Jul-Aug;63(1-2):41-6.

148. Brownell MD. Musically adapted social stories to modify behaviors in students with autism: four case studies. Journal of music therapy. 2002 Summer;39(2):117-44.

149. Gralinski JH, Kopp C. Everyday rules for behavior: Mother's requests to young children

Dev Psychol. 1993;29:573-84.

150. Rubin Z, Sloman J. How parents influence their children's friendships. In: Lewis M, ed. Beyond the dyad. New York: Plenum Press 1984:223-50.

151. Kaplan RS, Steele AL. An analysis of music therapy program goals and outcomes for clients with diagnoses on the autism spectrum. Journal of music therapy. 2005 Spring;42(1):2-19.

152. Whipple J. Music in intervention for children and adolescents with autism: a meta-analysis. Journal of music therapy. 2004 Summer;41(2):90-106.

153. Wigram T, Gold C. Music therapy in the assessment and treatment of autistic spectrum disorder: clinical application and research evidence. Child: care, health and development. 2006;32(5):535-42. 
Istvan Molnar-Szakacs, Ph.D. is a Research Neuroscientist at the Tennenbaum Center for the Biology of Creativity at the UCLA Semel Institute for Neuroscience and Human Behavior and member of the FPR-UCLA Center for Culture, Brain and Development. He received a Bachelor of Science with Honors from Dalhousie University, Canada, earned his Ph.D. in Neuroscience from UCLA and spent time as a post-doctoral fellow at the École Polytechnique Fédérale de Lausanne (EPFL) in Switzerland. His research uses behavioral and neuroimaging methods to study a variety of higher level cognitive functions including imitation, gesture perception, self-perception, emotion understanding, music perception and creativity. Dr. Molnar-Szakacs is also a certified yoga teacher.

Martha Wang, M.A., is a clinical psychology doctoral student at Fuller Theological Seminary School of Psychology. She has a B.A. in psychology and music from Scripps College. Her current research interests are interventions targeting social skill acquisition for children with autism spectrum disorders and the effects of music on children with autism.

Elizabeth A. Laugeson, Psy.D. is a licensed clinical psychologist and a Clinical Instructor in the Department of Psychiatry and Biobehavioral Sciences at the UCLA Semel Institute for Neuroscience and Human Behavior. Dr. Laugeson is the Director of The Help Group - UCLA Autism Research Alliance, which is a collaborative research initiative dedicated to developing and expanding applied clinical research in the treatment of children and adolescents with autism spectrum disorders. She is also the Director of the UCLA Early Childhood Clubhouse Program, a social recreational program for preschool children with autism spectrum disorders; is the Associate Director of the UCLA Parenting and Children's Friendship Program; and is the co-developer of an evidence-based social skills intervention for teens known as PEERS.

Dr. Katie Overy is a Senior Lecturer in Music, a founding co-director of the Institute for Music in Human and Social Development (IMHSD) and director of the MSc in Music in the Community at the University of Edinburgh. She studied Music at the University of Edinburgh (BMus), Music Psychology at the University of Sheffield (MA and PhD), and Music Pedagogy at the Kodaly Institute, Hungary (PG Dipl.). She conducted her post-doctoral work at Harvard Medical School, involving fMRI studies of rhythm and melody processing in young children and singing and speaking in aphasic patients. Katie has a long-standing interest in the role of music in human experience, with a focus on the relationship between language and music and an emphasis on interdisciplinarity and the integration of research and practice.

Wai-Ling Wu is an undergraduate student at the University of California, Los Angeles. She is entering her third year as a pre-psychology major, having just applied for the psychology major. Wai-Ling is interested in understanding various psychological disorders and phenomena. She is exploring different areas of research and clinical psychology and hopes to pursue a career in psychology.

Judith Piggot is an assistant professor of child and adolescent psychiatry at the University of California Los Angeles and Director of the Autism Evaluation Clinic. She has published several scientific journal articles on emotion attribution and neural heterogeneity in autism spectrum disorders. She obtained her Masters Degree in Genetics and her Ph.D. on the neural correlates of emotion attribution from facial expressions in high functioning individuals with social communication difficulties from the University of Glasgow, Scotland. She undertook her post-doctoral training focusing on the genetic and imaging correlates of emotion attribution in autism spectrum disorders in the Neuroimaging Laboratory, Department of Psychiatry, Stanford University. 